\title{
Notes on the vocalizations of Azure-hooded Jay (Cyanolyca cucullata)
}

\section{Peter Boesman}

In the following we briefly analyze and compare voice of the different races of Azure-hooded Jay (Cyanolyca cucullata). We also try to quantify the extent of any vocal differences using the criteria proposed by Tobias et al. (2010), as a support for taxonomic review. We have made use of sound recordings available on-line from Xeno Canto (XC) and Macaulay Library (ML).

An overview of the vocalizations per race:

\section{$\underline{\text { Race mitrata }}$}

A nasal drawn-out "nyeeh"

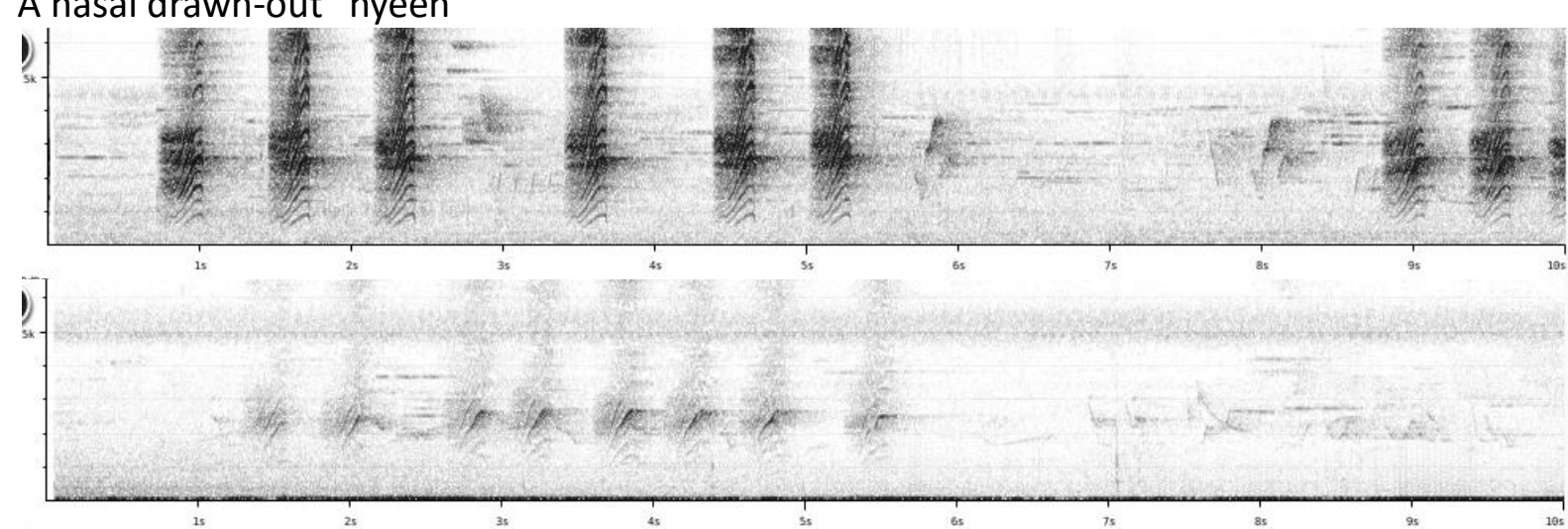

A fast series of somewhat plaintive upslurred notes "king..king..king"

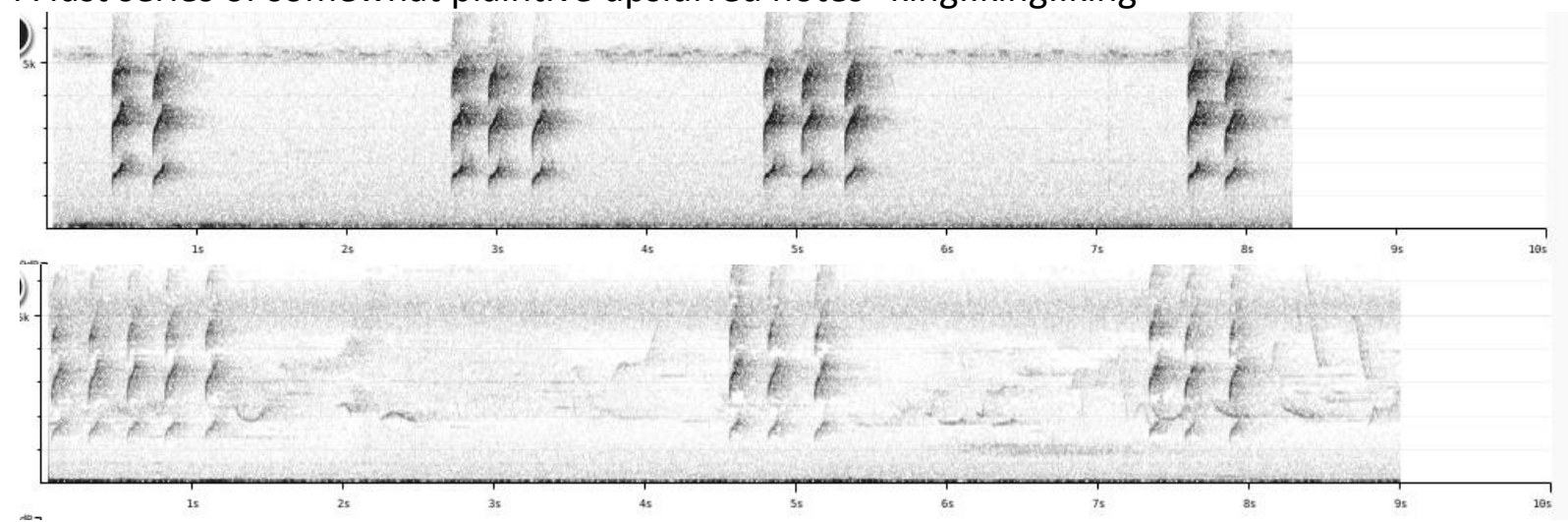

\section{Race quatemalae}

A nasal drawn-out "nye-eh"

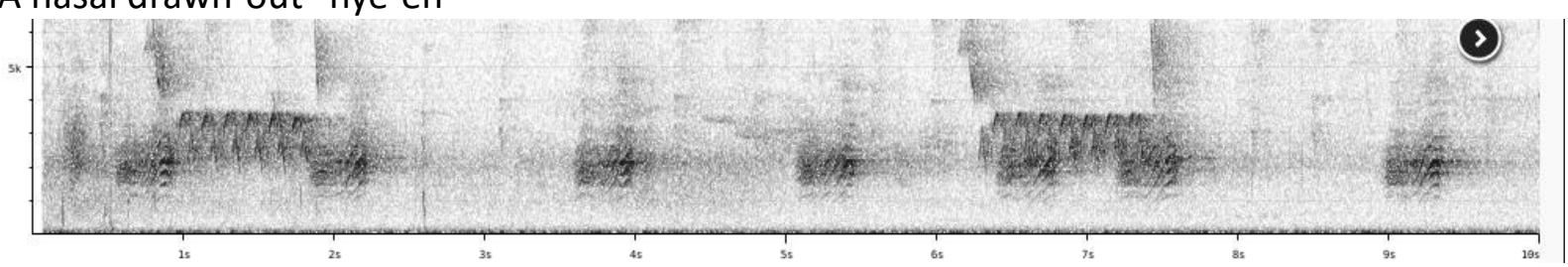




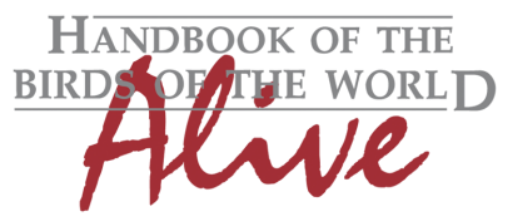

\section{ORNITHOLOGICAL NOTES}

A fast short series of somewhat plaintive upslurred notes "king..king"

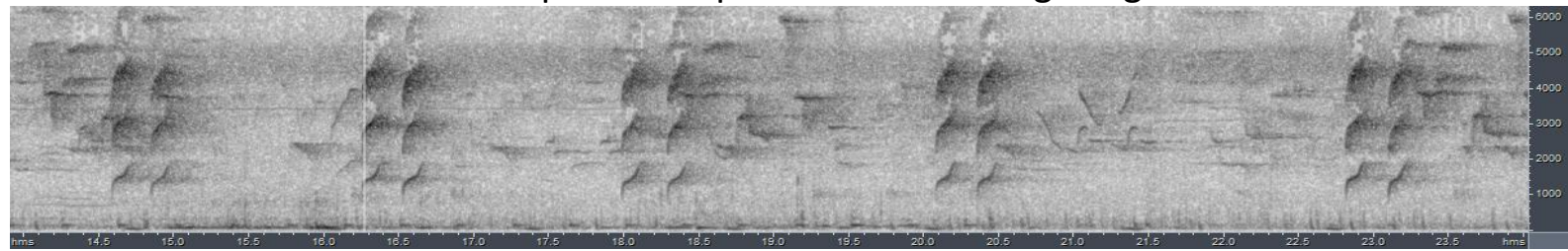

\section{Race hondurensis}

A nasal drawn-out "nye-eh"

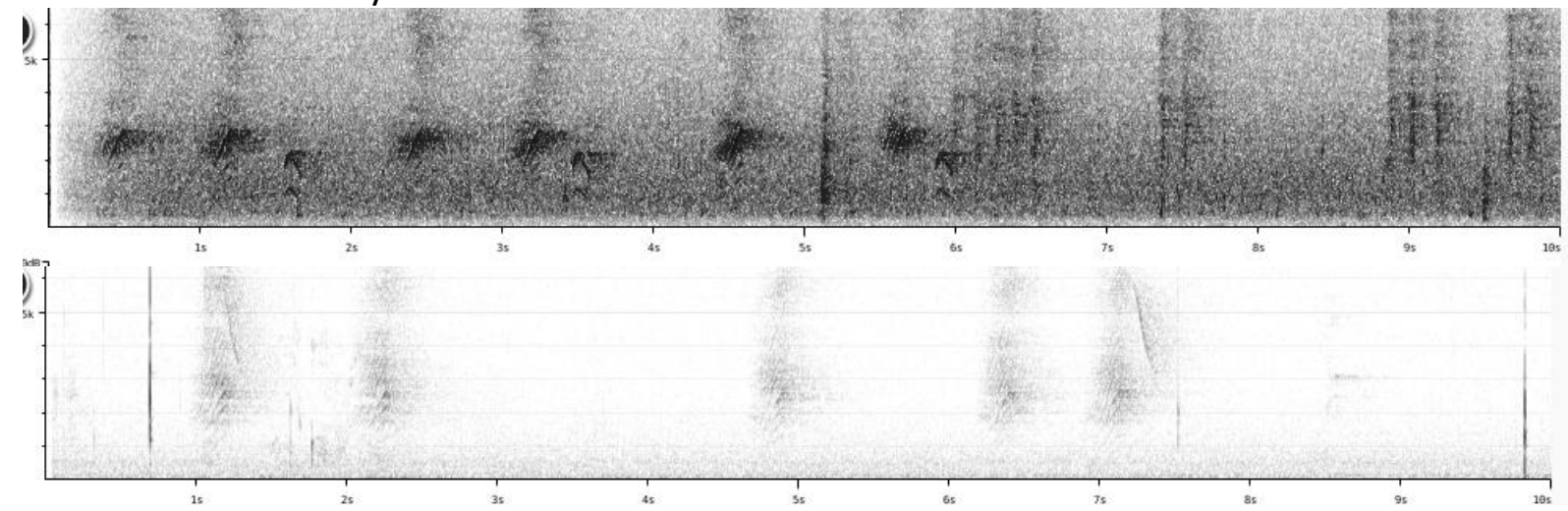

Race cucullata

A gruff drawn-out "krrrr" (without the upslurred ending as in previous races)

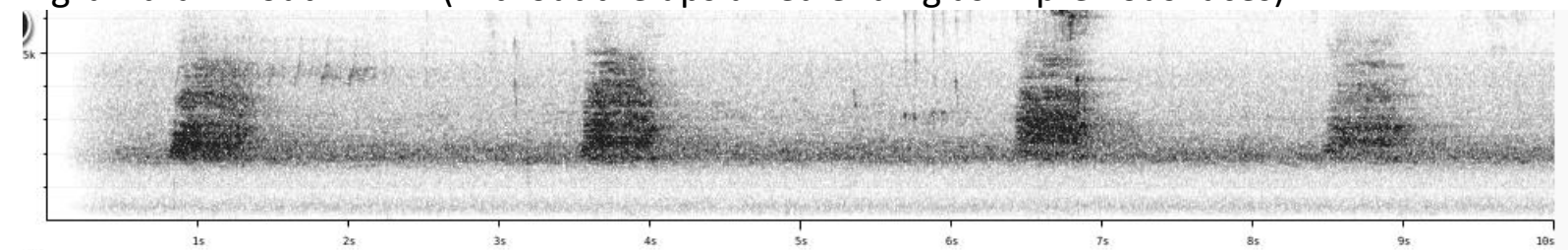

A fast series of rather piercing notes "kra-kee-kee-kee" (common vocalization)

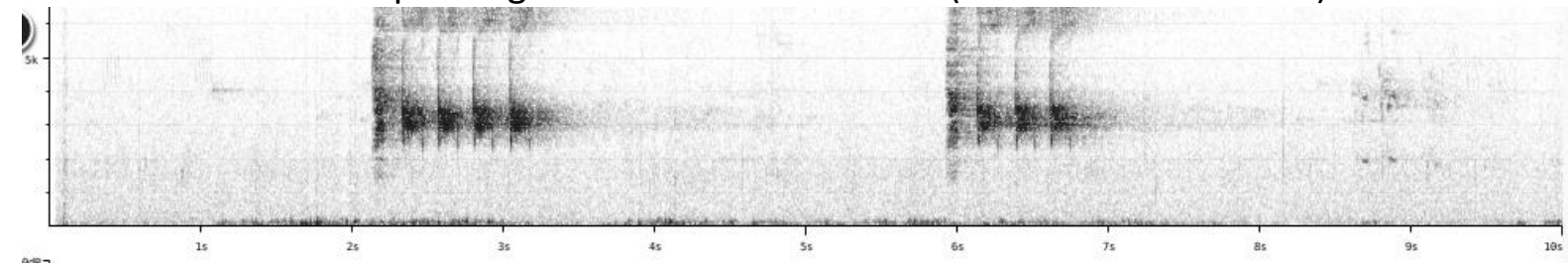

A fast series of piping notes "pyee-pyee-pyee-pyee.." (higher-pitched than mitrata)

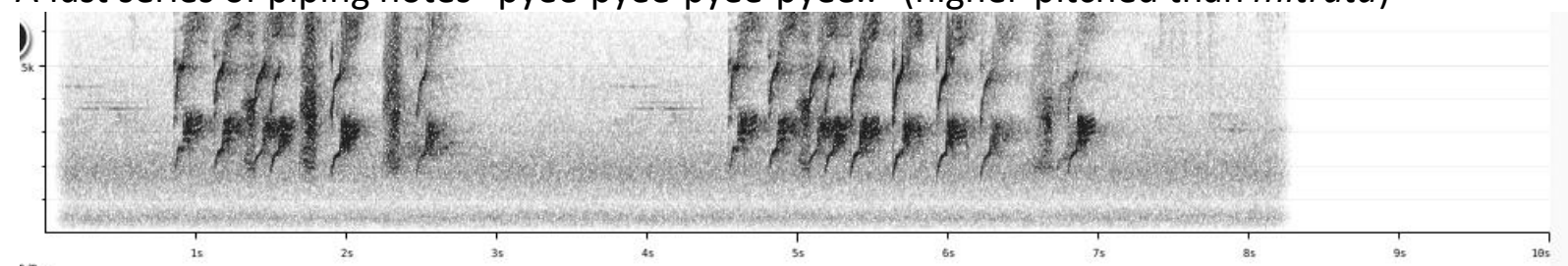

It would thus seem that vocally it is rather race cucullata which is distinct (which is not in line with morphological differences, where mitrata is the distinct race). 

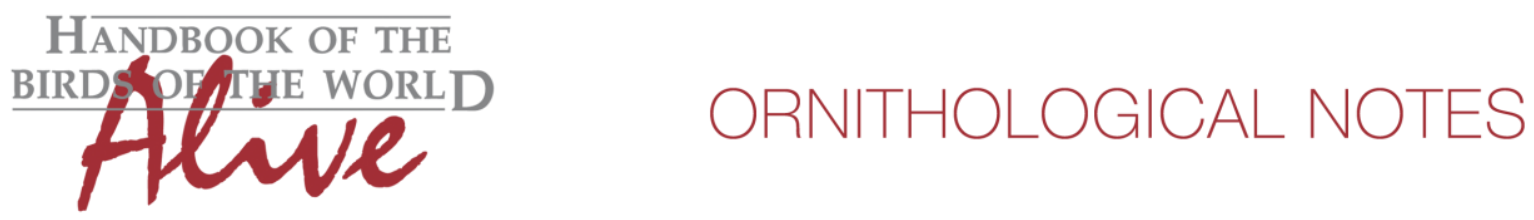

As a matter of fact, there is a consistent difference in the two main vocalizations:

* The scratchy call is distinctly upslurred at the end and more nasal in the three northern races (measurable difference 'end freq. - start freq.',score 2)

* The fast note series are distinctly higher-pitched in cucullata with different note shape (max. freq. c. $3.5 \mathrm{kHz}$ vs max. freq. c. $2 \mathrm{kHz}$, score 2-3).

When applying Tobias criteria, this would lead to a total vocal score of about 4.

This note was finalized on 28th January 2016, using sound recordings available on-line at that moment. We would like to thank in particular the sound recordists who placed their recordings for this species on XC and ML: Alfonso Auerbach, Peter Boesman, Irby Davis, Samuel Jones, Oliver Komar, Ted Parker, David Ross, Roberto Sosa, Andrew Spencer, Arnoud van den Berg, Charlie Vogt, George Wagner and Sam Woods.

\section{References}

Tobias, J.A., Seddon, N., Spottiswoode, C.N., Pilgrim, J.D., Fishpool, L.D.C. \& Collar, N.J. (2010). Quantitative criteria for species delimitation. Ibis 152(4): 724-746.

\section{Recommended citation}

Boesman, P. (2016). Notes on the vocalizations of Azure-hooded Jay (Cyanolyca cucullata). HBW Alive Ornithological Note 210. In: Handbook of the Birds of the World Alive. Lynx Edicions, Barcelona. (retrieved from http://www.hbw.com/node/932159 on 3 September 2016). 